7. Reprod. Fert. (1967) 13, 259-267

\title{
A STUDY OF THE EARLY STAGES OF IMPLANTATION IN MICE
}

\author{
C. A. FINN* AND ANNE MaLAREN \\ Department of Biological Sciences, Wye College (University of London), Ashford, Kent, \\ and A.R.C. Unit of Animal Genetics, Institute of Animal Genetics, \\ West Mains Road, Edinburgh
}

(Received 1st July 1966)

\begin{abstract}
Summary. In order to study the changes taking place in the blastocyst and locally in the uterus at the site of the blastocyst attachment, pregnant mice were killed at intervals between 3 days $21 \mathrm{hr}$ and 4 days $16 \mathrm{hr}$ post coitum. The uteri were tested for the presence of Pontamine Blue areas (indicating increased permeability of capillaries) and histochemically for alkaline phosphatase in the stroma, and also examined histologically. By classifying each female for the various features studied, the following order of appearance was established: Pontamine Blue reactivity, 'Wbodies' emerging from blastocyst, local oedema of the uterine stroma, alkaline phosphatase in the uterine stroma, histological decidualization. Giant cell transformation of the trophoblast occurred at about the same time as the emergence of $\mathrm{W}$-bodies from the blastocyst. Blastocyst elongation began after the appearance of Pontamine Blue reactivity and before histological decidualization, but was not sequentially related to the other features studied.
\end{abstract}

\section{INTRODUCTION}

Implantation of ova in rodents involves a complex series of morphological and biochemical interactions between the blastocyst and the uterus, culminating in the attachment of the embryo to the mother by means of the placenta. Recently three separate local reactions have been demonstrated to occur soon after the blastocyst makes contact with the endometrium. Psychoyos (1961) showed, originally in rats, that the blood vessels near the site of an implanting blastocyst become more permeable, so that after the injection of a large molecular weight dye, such as Pontamine Sky Blue, a coloured band appears across the uterus where a blastocyst is present. This reaction occurs before any other macroscopic evidence of implantation can be seen in the uterus. Secondly Wilson (1963) demonstrated the passage of cells, which he called 'primary invasive cells', from the blastocyst into the uterine epithelium, and thirdly Finn \& Hinchliffe (1964) showed that the enzyme alkaline phosphatase appeared in the endometrial stroma around an implanting blastocyst. Histo-

* Present address: Department of Physiology, Royal Veterinary College, Royal College Street, London, N.W.1. 
logically, the uterine stroma around an implanting blastocyst shows marked oedema at an early stage, with the formation of the 'primary decidual zone', consisting of closely packed cells around the uterine lumen, following later (Krehbiel, 1937).

The object of the present experiments was to study these reactions in the same animals in order to obtain information about the order in which they appeared. This is a necessary preliminary to any causal analysis of the processes involved. In particular, the question of how the uterus is stimulated to respond locally to the presence of a blastocyst is still open. Blandau (1949) reported that placing glass and paraffin beads in the uterus would induce decidual changes in rats and guinea-pigs; this has often been interpreted as demonstrating that it is the pressure of the blastocyst against the uterine epithelium which is the effective stimulus in normal pregnancy. However, there are almost certainly other factors involved, since unfertilized mouse ova (Orsini \& McLaren, unpublished), dead rat blastocysts (Segal \& Nelson, 1958) and fixed sea-urchin ova (Alden \& Smith, 1959) all fail to induce a decidual response.

The basically staining RNA-rich bodies contained in Wilson's 'primary invasive cells' are easily seen under the microscope. The cells themselves, however, are not so easy to see. We shall therefore refer throughout not to 'primary invasive cells', but to 'W-bodies', a term which makes no assumptions about their function.

\section{MATERIAL AND METHODS}

Females belonged to the randomly bred $Q$ strain, and were nulliparous. They were paired with males of their own strain in the afternoon, examined for copulation plugs the following morning, and killed between 3 days $21 \mathrm{hr}$ and 4 days $16 \mathrm{hr}$ post coitum (assuming coitus took place at 01.00 hours during the night of mating). 'The experiment was carried out in two parts, the first in August and the second in November; the two batches of mice did not differ significantly from one another, and have therefore been combined.

Fifteen minutes before each animal was killed, $0.25 \mathrm{ml}$ of a $1 \%$ solution of Pontamine Sky Blue 5BX was injected intravenously. The position, intensity and number of blue areas in the two uterine horns was recorded after death. One uterine horn of each animal was fixed in cold $80 \%$ alcohol; after remaining overnight in a refrigerator these horns were posted in ice from Edinburgh to Wye, where they were sectioned and examined for the presence of alkaline phosphatase by the Gomori technique. The other horn of each female was fixed in either AFA (30 ml 95\% alcohol, $10 \mathrm{ml}$ commercial formalin, $10 \mathrm{ml}$ glacial acetic acid, $50 \mathrm{ml}$ water) or in Carnoy's fluid; these horns were cleared according to the method described by Orsini (1962a, b) so that the Pontamine Sky Blue areas could be examined more closely; they were then serially sectioned, stained with Iron Haematoxylin or with Methyl Green and Toluidine Blue, and examined histologically. All blastocysts in these sections were photographed, so that they could be more readily compared. Left and right horns were allotted alternately to the two treatments.

Pontamine Blue reactions were recorded as: - (no blue areas), + ? (blue 
areas, too faint to count accurately), + (faint blue areas), ++ (strong blue areas, +++ (strong blue areas, with central opacity visible after clearing). Alkaline phosphatase reactions of the uterine stroma were recorded as: - (negative) + (faintly positive), ++ (strongly positive) (Pl. 1, Figs. 1 to 4 ). Localized oedema of the stroma was recorded as: - (absent) or + (present) (Pl. 2, Figs. 2 and 4). The decidual response of the uterine endometrium was classified as: - (absent) or + (present) (Pl. 2, Fig. 6). Blastocysts were classified as round, oval or elongate (Pl. 2, Figs. 1, 3 and 5). Where the blastocyst itself was distorted, its original shape could often be deduced from the form of the uterine chamber. Emerging W-bodies (Pl. 3, Figs. 1 to 7) were recorded as: - (absent), + ? (sparse and dubious), + (sparse and definite),++ (numerous and definite). Both authors independently examined the sectioned uteri for $\mathrm{W}$-bodies; their classifications were in good agreement.

\section{RESULTS}

Of the twenty-nine females, three were not pregnant (one of these had unfertilized eggs in the uterus). Data on the remaining twenty-six are listed in Table 1, in order of time of killing. Six showed no response to the test for alkaline phosphatase, even in the serosal region which is normally strongly positive. All alkaline phosphatase must therefore have been inactivated, probably as a result of overheating in transit. Three other uteri were lost in transit before they could be examined histologically for the presence of W-bodies and decidual response. The uterine horns tested for the presence of alkaline phosphatase and those examined histologically had shown an average of 4.2 and 4.5 Pontamine Blue areas respectively. One hundred blastocysts were examined for W-bodies.

There was some variability within uterine horns, particularly with respect to blastocyst shape. This is indicated in Table 1. In female 12, one implantation site showed alkaline phosphatase in the stroma, while the other three sites in the horn were negative. In female 5, one blastocyst was at an earlier stage of development than the other four, and still showed remnants of the zona pellucida. It was not associated with a Pontamine Blue area. In female 11, one of the two blastocysts was very advanced in development, and showed no W-bodies; the other was less advanced, and showed W-bodies.

In females 19 and 20, the blastocysts in the uterine horn examined histologically were clustered near the middle of the horn. In the other females, they were spread along the length of the horn. On three occasions (females 8, 10 and 19), two blastocysts were found sharing the same implantation chamber (Pl. 2, Fig. 7).

\section{The Pontamine Blue reaction}

As may be seen from Table 1 the Pontamine Blue reaction was already evident at 22.15 hours, when the first mouse was killed. Of the thirteen females killed up to midnight, two were negative, seven were faintly positive and four strongly positive. Of the thirteen killed after midnight, one was negative, three faintly positive and nine strongly positive. In the three negative females, all the blastocysts were circular in cross-section, and there were no emerging W-bodies, 
TABLE 1

OBSERVATIONS ON FEMALE MICE KILLED DURING THE 4TH NIGHT AND 5TH DAY AFTER A COPULATION PLUG HAD BEEN FOUND

\begin{tabular}{|c|c|c|c|c|c|c|c|}
\hline Female & $\begin{array}{l}\text { Time of } \\
\text { killing } \\
(G M T)\end{array}$ & $\begin{array}{c}\text { Pontamine } \\
\text { Blue }\end{array}$ & Blastocysts & $\begin{array}{l}W \text {-bodies } \\
\text { emerging }\end{array}$ & $\begin{array}{c}\text { Alkaline } \\
\text { phosphatase }\end{array}$ & Oedema & $\begin{array}{l}\text { Decidual } \\
\text { response }\end{array}$ \\
\hline $\begin{array}{r}1 \\
2 \\
3 \\
4 \\
5 \\
6 \\
7 \\
8 \\
9 \\
10 \\
11 \\
12 \\
13 \\
14 \\
15 \\
16 \\
17 \\
18 \\
19 \\
20 \\
21 \\
22 \\
23 \\
24 \\
25 \\
26\end{array}$ & $\begin{array}{l}22.15 \\
22.45 \\
22.45 \\
23.00 \\
23.00 \\
23.15 \\
23.15 \\
23.30 \\
23.30 \\
23.45 \\
23.45 \\
24.00 \\
24.00 \\
00.15 \\
00.15 \\
00.30 \\
00.45 \\
00.45 \\
01.00 \\
01.15 \\
08.30 \\
09.30 \\
11.00 \\
14.00 \\
17.00 \\
17.15\end{array}$ & $\begin{array}{c}++ \\
+ \\
+ \\
+? \\
+ \\
+ \\
+ \\
++ \\
+? \\
++ \\
+ \\
++ \\
+ \\
++ \\
+ \\
++ \\
++ \\
+ \\
+? \\
++ \\
++ \\
++ \\
++ \\
++ \\
++\end{array}$ & $\begin{array}{l}\text { Oval } \\
\text { Round, oval } \\
\text { Round, oval } \\
\text { Round } \\
\text { Round, oval } \\
\text { Round } \\
\text { Round, oval } \\
\text { Round } \\
\text { Round } \\
\text { Round, oval } \\
\text { Round, oval } \\
\text { Oval } \\
\text { Oval } \\
\text { Oval } \\
\text { Round, oval } \\
\text { Round, oval } \\
\text { Oval } \\
\text { Round } \\
\text { Round } \\
\text { Round } \\
\text { Elongate } \\
\text { Round } \\
\text { Oval } \\
\text { Oval } \\
\text { Elongate } \\
\text { Round }\end{array}$ & $\begin{array}{l}+ \\
+ \\
- \\
+ \\
+ \\
+ \\
+ \\
+ \\
+ \\
+ \\
+ \\
++ \\
+ \\
+ \\
++ \\
+ \\
+ \\
\overline{+} \\
+? \\
++ \\
(-)^{*}\end{array}$ & $\begin{array}{c}- \\
- \\
- \\
- \\
- \\
- \\
++ \\
+ \\
+ \\
+ \\
+ \\
+ \\
- \\
++ \\
+ \\
++ \\
++ \\
++\end{array}$ & $\begin{array}{l}- \\
- \\
- \\
- \\
+ \\
- \\
= \\
+ \\
+ \\
+ \\
+ \\
+ \\
+ \\
+ \\
+ \\
+ \\
+ \\
+ \\
+ \\
+ \\
+ \\
+ \\
+\end{array}$ & $\begin{array}{l}z \\
z \\
z \\
z \\
- \\
- \\
z \\
- \\
+ \\
\pm \\
- \\
- \\
- \\
= \\
- \\
\overline{-} \\
+ \\
+ \\
+\end{array}$ \\
\hline
\end{tabular}

* In Tables 2 and 3, female 23 is omitted, as the absence of W-bodies is probably secondary.

TABLE 2

THE NUMBERS OF UTERI FOUND WITH NEGATIVE, FAINTLY POSITIVE OR STRONGLY POSITIVE REACTIONS WITH PONTAMINE BLUE, CLASSIFIED WITH RESPEGT TO THE OTHER CHANGES STUDIED (DATA EXTRACTED FROM TABLE 1)

\begin{tabular}{|c|c|c|c|c|c|}
\hline & & \multicolumn{3}{|c|}{ Pontamine Blue } & \multirow{2}{*}{$\begin{array}{c}\text { No. of females } \\
\text { classified for } \\
\text { both }\end{array}$} \\
\hline & & - & + &,+++++ & \\
\hline W-bodies &, \pm++ & $\begin{array}{l}0 \\
3\end{array}$ & $\begin{array}{l}7 \\
3\end{array}$ & $\begin{array}{l}8 \\
0\end{array}$ & 21 \\
\hline Oedema & \pm & $\begin{array}{l}0 \\
3\end{array}$ & $\begin{array}{l}6 \\
4\end{array}$ & $\begin{array}{l}9 \\
1\end{array}$ & 23 \\
\hline $\begin{array}{l}\text { Blastocyst } \\
\text { shape }\end{array}$ & $\begin{array}{l}\text { Elongate } \\
\text { Oval } \\
\text { Round and oval } \\
\text { Round }\end{array}$ & $\begin{array}{l}0 \\
0 \\
0 \\
3\end{array}$ & $\begin{array}{l}0 \\
2 \\
6 \\
2\end{array}$ & $\begin{array}{l}2 \\
5 \\
2 \\
4\end{array}$ & 26 \\
\hline $\begin{array}{l}\text { Alkaline- } \\
\text { phosphatase }\end{array}$ & $\begin{array}{l}++ \\
+\end{array}$ & $\begin{array}{l}0 \\
0 \\
2\end{array}$ & $\begin{array}{l}0 \\
2 \\
8\end{array}$ & $\begin{array}{l}5 \\
2 \\
1\end{array}$ & 20 \\
\hline $\begin{array}{l}\text { Decidual } \\
\text { response }\end{array}$ & \pm & $\begin{array}{l}0 \\
3\end{array}$ & $\begin{array}{l}1 \\
9\end{array}$ & $\begin{array}{l}3 \\
7\end{array}$ & 23 \\
\hline
\end{tabular}


oedema or positive alkaline phosphatase reactions. The time of appearance of the other changes, relative to the Pontamine Blue reaction, is summarized in Table 2.

\section{The alkaline phosphatase reaction}

The alkaline-phosphatase results correlated rather well with the time of killing. The first positive reaction was seen in the mouse killed at 23.45 hours. By the following morning, all the mice successfully tested were positive $(5 / 5)$. The relationship between the time of appearance of alkaline phosphatase and the Pontamine Blue reaction is shown in Table 2 . The two are closely correlated, but the Pontamine Blue reaction clearly occurs first.

Alkaline phosphatase activity in the uterine endometrium first appeared as a positive area in the stroma in the neighbourhood of the blastocyst. In the early responses the activity was present, not in the area of stroma immediately adjacent to the epithelium, but as a crescent-shaped area in the middle of the subendometrial stroma (Pl. 1, Figs. 2 and 3). This had not been observed in the earlier study (Finn \& Hinchliffe, 1964); there, however, the first responses were not examined until the morning of the 5 th day post coitum, so that the initiation of the response, which from the present data appears to start during the previous night, had been overlooked.

Alkaline phosphatase is present in the blastocysts before it can be detected in the uterine stroma, and in early specimens is found around the entire circumference, indicating perhaps the continued presence of the zona pellucida. In the later stages, at about the time of its appearance in the uterine stroma, alkaline phosphatase disappears from the abembryonic regions of the blastocyst, except for an occasional cell, but the inner cell mass remains strongly positive.

\section{The migration of $W$-bodies}

W-bodies were most clearly seen in the epithelium after staining with Toluidine Blue, but they were also fairly readily identified after staining with ironhaematoxylin. With the light microscope they appeared as specks of basically staining material in which it was not possible to differentiate any internal structure. They varied considerably in shape, some being circular whilst others were elongated in the more typical form described by Wilson (1963). It was usual to find more than one in each blastocyst, and sometimes as many as a dozen were found. Cells containing W-bodies were sometimes observed in the wall of the blastocysts, but only in those specimens from which other W-bodies were already emerging. Wilson (1963) reported the presence of cells, which he believed to be identical with the primary invasive cells later to be seen in the trophoblast, in the inner cell mass up to $12 \mathrm{hr}$ earlier than the earliest stages studied here.

Emerging W-bodies were always accompanied by a positive Pontamine Blue reaction, but in at least six cases (Nos. 2, 5, 7, 10, 13 and 16) their emergence preceded the development of a positive alkaline-phosphatase reaction. The apparent absence of $\mathrm{W}$-bodies in the later stages of the implantation reaction, e.g. female 23, is consistent with the findings of Wilson (1963), and is probably due to the difficulty of detecting them once the decidual reaction has started. 
Blastocyst morphology

The changes in the appearance of the blastocysts were fairly well correlated with the other reactions. Thus $3 / 7$ uteri in which only round blastocysts were found showed an alkaline-phosphatase reaction, and 3/8 showed W-bodies, whereas in uteri containing only oval or elongated blastocysts, the corresponding proportions were $5 / 6$ and $5 / 6$, respectively. On the other hand, blastocyst morphology was very variable with respect to time; the first female killed contained oval blastocysts, whereas in two out of the six animals killed on the 5th day the blastocysts were round.

The trophoblastic giant cell reaction (Dickson, 1963) was closely correlated with the emergence of the W-bodies. The time of loss of the zona pellucida could not be ascertained with any certainty as the zona is removed completely by AFA and partially by Carnoy's fluid. Traces of zonae were seen around the blastocysts of females 8,19 and 20 .

\section{Oedema and decidual reactions}

Like the alkaline-phosphatase reaction, the appearance of oedema in the uterine stroma showed good correlation with the time of killing. Thus, of the twenty-three females studied, only one killed before 23.30 hours (Table 1) showed oedema, whereas only two of those killed after that time failed to show it.

Of the nine females not showing oedema, six were positive for Pontamine Blue, and three already showed the presence of $\mathrm{W}$-bodies in the uterine epithelium. None of the females without oedema showed a positive alkaline phosphatase reaction, but four with oedema had not yet developed alkaline phosphatase. On the other hand, the massing of stroma cells around the anti-mesometrial side of the uterine lumen, which was taken as indicative of the beginning of the decidual response, occurred after the appearance of alkaline phosphatase. The four mice showing a decidual response (Table 1) were all positive for alkaline phosphatase, but one female positive for alkaline phosphatase (No. 18) had not yet developed any histological signs of decidualization.

\section{DISGUSSION}

Our results present a consistent picture of the chronology of the early stages of implantation in the mouse. In the strain of mice used, the Pontamine Blue reaction, an index of locally increased capillary permeability, was positive in the majority of pregnant females before midnight on the 4th day post coitum. In the present study, this was the earliest indication that the uterus was reacting locally to the presence of a blastocyst. The time of appearance of the Pontamine Blue reaction is consistent with that reported by Orsini \& McLaren (1967).

The relative ordering of the phenomena studied can best be appreciated if the data are displayed as in Table 3 . All the females examined fall into one or other of the six 'stages' (though one or two females have been omitted from the Table on account of incomplete classification). The fact that the females can be so arranged implies that, as far as the present data are concerned, the five characters listed in Table 3 are sequentially dependent, that is, a female showing 
any one will also show all those earlier in the list. (This need not necessarily mean that they are also causally dependent.) Change of shape of the blastocyst, on the other hand, is independent of most of the characters listed: blastocyst elongation was not seen in stage-1 females, and was present in all stage- 6 females, but stages 2, 4 and 5 all include some females containing only round blastocysts, and others in which elongation had begun.

The appearance of alkaline phosphatase in the uterine stroma, indicating that this has become a region of increased cellular activity, followed the Pontamine Blue reaction by not more than a few hours. The localization of the early alkaline phosphatase reaction is puzzling: the initial signal for activity

TABLE 3

THE SEQUENTIAL DEPENDENGE OF THE OBSERVED GHANGES

\begin{tabular}{c|c|c|c|c|c|c}
\hline Stage & $\begin{array}{c}\text { Pontamine } \\
\text { Blue }\end{array}$ & W-bodies & $\begin{array}{c}\text { Stromal } \\
\text { oedema }\end{array}$ & $\begin{array}{c}\text { Alkaline } \\
\text { phosphatase }\end{array}$ & $\begin{array}{c}\text { Decidual } \\
\text { response }\end{array}$ & \multicolumn{1}{|c}{ Females } \\
\cline { 3 - 6 } & - & - & - & - & - & $(6), 8,19$ \\
2 & + & - & - & - & - & $3,4,20$ \\
3 & + & + & - & - & - & $(1), 2,7$ \\
4 & + & + & + & - & - & $5,10,13,16$ \\
5 & + & + & + & + & - & $14,18,22$ \\
6 & + & + & + & + & + & $11,12,21$ \\
\hline
\end{tabular}

Numbers in parentheses indicate females which were not classified for alkaline phosphatase activity. Females 9,15 and 17, also unclassified for alkaline phosphatase activity, have been omitted since they could have belonged either to stage 4 or to stage 5 .

to begin must come from the blastocyst in the uterine lumen, yet it was not those regions of the stroma adjacent to the lumen which showed the reaction first. Possibly the initial distribution of alkaline phosphatase is related to the pattern of vascularization of the stroma.

The emergence of W-bodies from the blastocyst and their penetration into the uterine epithelium appeared to take place before the appearance of the alkaline phosphatase but after the Pontamine Blue reaction. If this is confirmed it would mean that the $\mathrm{W}$-bodies are not responsible for informing the uterus that a blastocyst is present. We therefore remain in ignorance both of the function of these remarkable objects, and of the nature of the initial signal from blastocyst to uterus.

\section{ACKNOWLEDGMENTS}

We gratefully acknowledge financial support from the Ford Foundation (A.McL.) and the Medical Research Council (C.A.F.), and would like to thank Mr K. Barber for his technical assistance.

\section{REFERENCES}

ALDEN, R. H. \& SMrth, M. J. (1959) Implantation of the rat egg. IV. Some effects of artificial ova on the rat uterus. F. exp. Zool. 142, 215.

Blandau, R. J. (1949) Embryo-endometrial interrelationship in the rat and guinea pig. Anat. Rec. 104, 331. 
Dickson, A. D. (1963) Trophoblastic giant cell transformation of mouse blastocysts. F. Reprod. Fert. 6, 465.

Finn, C. A. \& Hinchlipfe, J. R. (1964) Reaction of the mouse uterus during implantation and deciduoma formation as demonstrated by changes in the distribution of alkaline phosphatase. $\mathcal{F}$. Reprod. Fert. 8, 331.

KrehbieL, R. H. (1937) Cytological studies of the decidual reaction in the rat during early pregnancy and in the production of deciduomata. Physiol. Zool. 10, 212.

Orsini, M. W. (1962a) Technique of preparation, study and photography of benzyl-benzoate cleared material for embryological studies. F. Reprod. Fert. 3, 283.

Orsini, M. W. (1962b) Study of ova-implantation in the hamster, rat, mouse, guinea-pig and rabbit in cleared uterine tracts. 7. Reprod. Fert. 3, 278.

Orsini, M. W. \& McLaren, A. (1967) Loss of the zona pellucida in mice, and the effect of tubal ligation and ovariectomy. F. Reprod. Fert. (In press).

Psychoyos, A. (1961) Perméabilité capillaire et décidualization utérine. C. r. hebd. Séanc. Acad. Sci., Paris, 252, 1515.

Segal, S. J. \& Nelson, W. O. (1958) An orally active compound with antifertility effects in rats. Proc. Soc. exp. Biol. Med. 98, 431.

WiLson, I. B. (1963) A new factor associated with the implantation of the mouse egg. F. Reprod. Fert. 5,281 .

\section{EXPLANATION OF PLATES}

\section{Plate 1}

Fig. 1. Transverse section of uterus of female 3 , negative for alkaline phosphatase activity in the uterine stroma. Note the presence of alkaline phosphatase activity in the serosa, around the uterine glands, and in the blastocyst. $\times 70$.

FIg. 2. Transverse section of uterus of female 14, faintly positive for alkaline phosphatase activity in the uterine stroma. Note the oedema in the outer areas of the mucosa, contrasting with the closely.packed cells around the uterine lumen ( = primary decidual zone). The alkaline phosphatase activity begins near the outer margin of the expanding primary decidual zone. $\times 70$.

Frg. 3. High power view of Fig. 2, to show early distribution of alkaline phosphatase activity. $\times 200$.

Fig. 4. Transverse section of uterus of female 24, strongly positive for alkaline phosphatase activity in the uterine stroma. $\times 60$.

\section{Plate 2}

Fig. 1. 'Round' blastocyst, from female 15. Although the blastocyst is crumpled, its original shape can be deduced from the shape of the anti-mesometrial chamber in which it is situated. Here and in all the other figures, the space in the uterine lumen and between the blastocyst and the uterine epithelium is a shrinkage artefact. In vivo, the walls of the uterine lumen are pressed tightly together at this stage of pregnancy, $\times 220$.

Fig. 2. Transverse section of uterus of female 5 , to show oedema of the uterine stroma. $\times 70$. FIG. 3. 'Oval' blastocyst, from female 3. $\times 300$.

Fic. 4. High power view of uterine stroma of female 13 , to show oedema. $\times 300$.

Fic. 5. 'Elongate' blastocyst, from female 21. $\times 220$.

Fig. 6. Transverse section of uterus of female 21 , showing enlarging area of cellular hyperplasia around the uterine lumen (= primary decidual zone). This female was classified as showing a decidual response. The decidual cell reaction is not yet evident. $\times 70$.

FIG. 7. Transverse section of uterus of female 19, showing two blastocysts in a single antimesometrial chamber. The corrugated border to the uterine lumen where the walls are pressed together is characteristic of this stage of pregnancy or pseudopregnancy, and is not a local reaction to the presence of a blastocyst. $\times 300$. 


\section{PLATE 1}

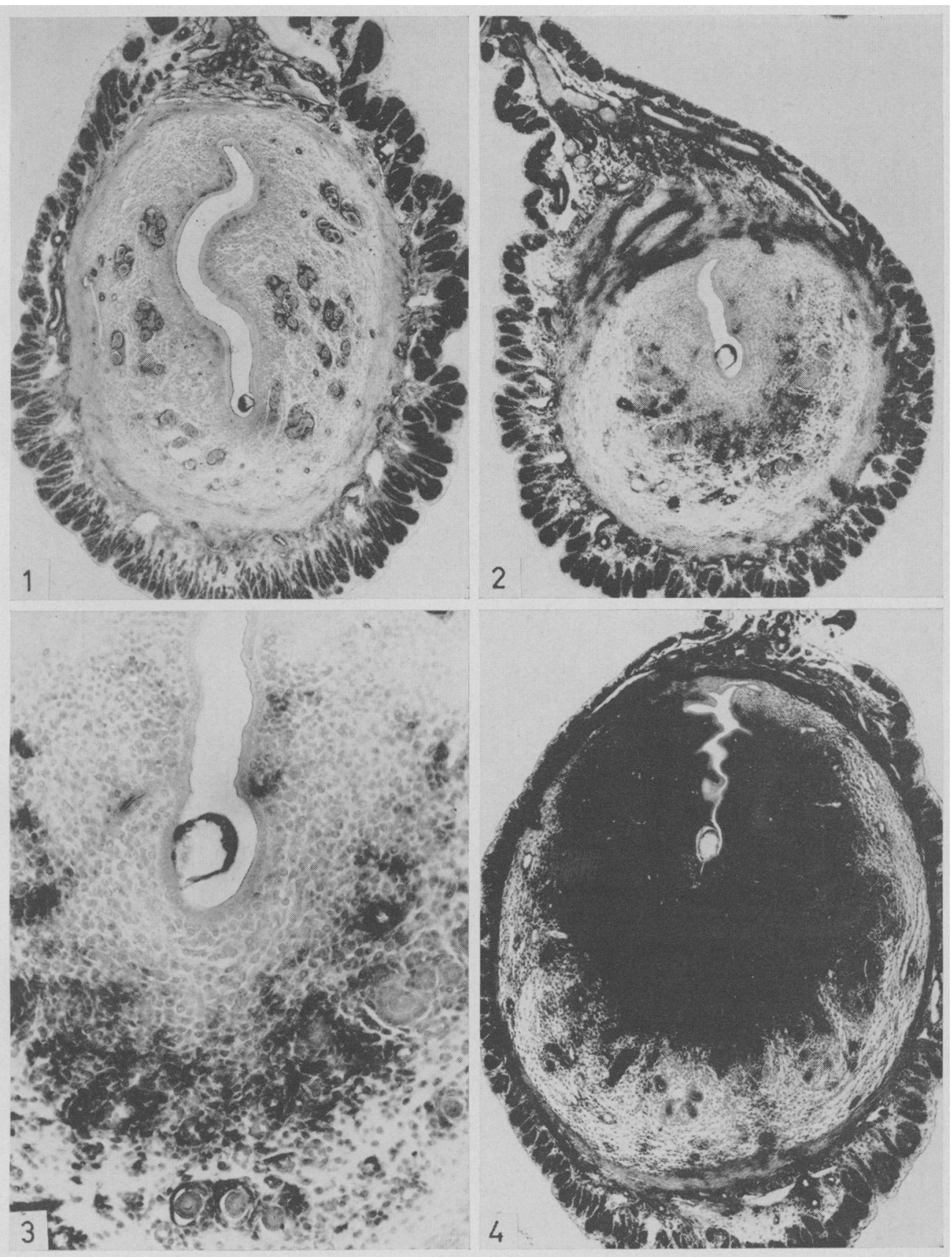


PIATE 2

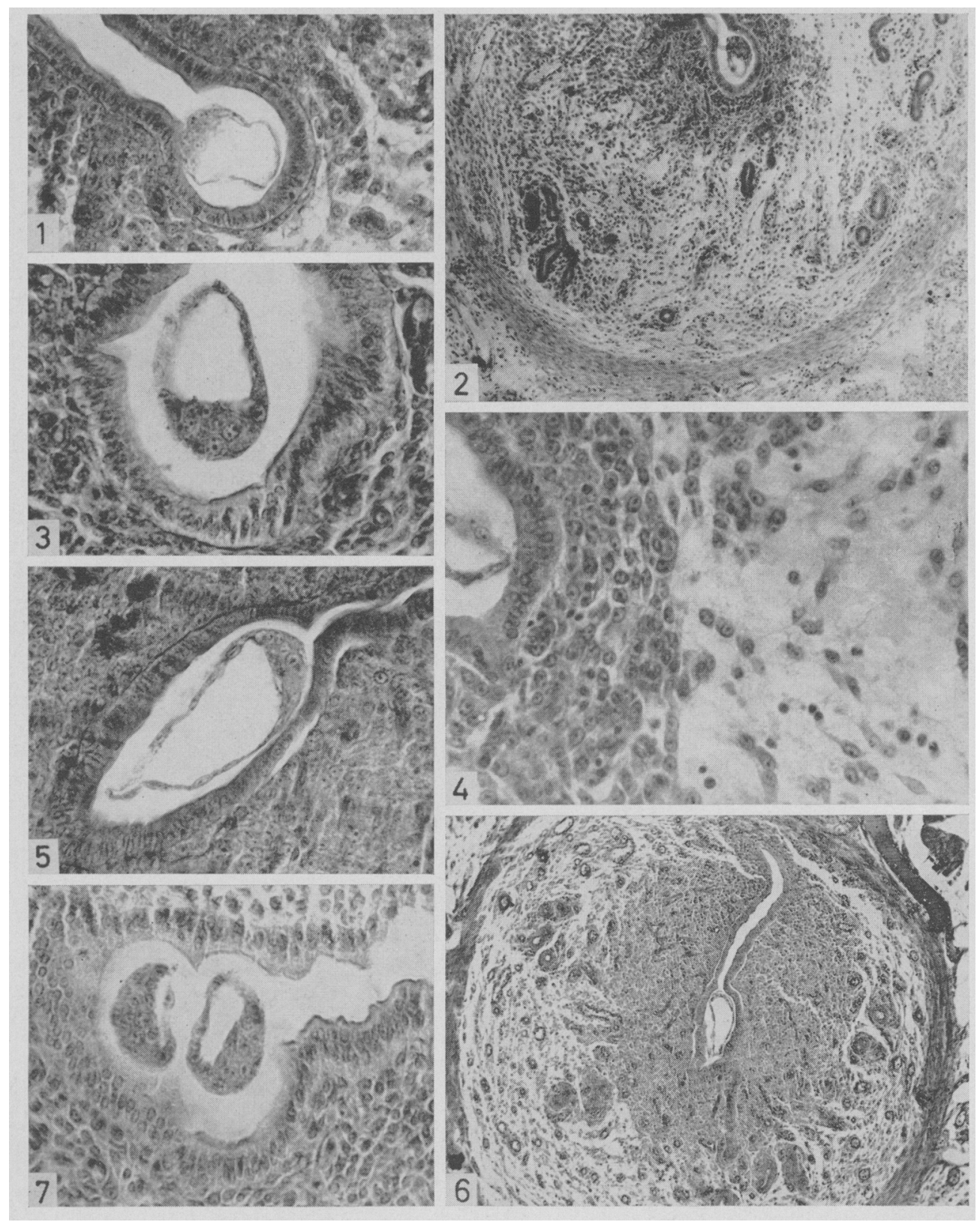




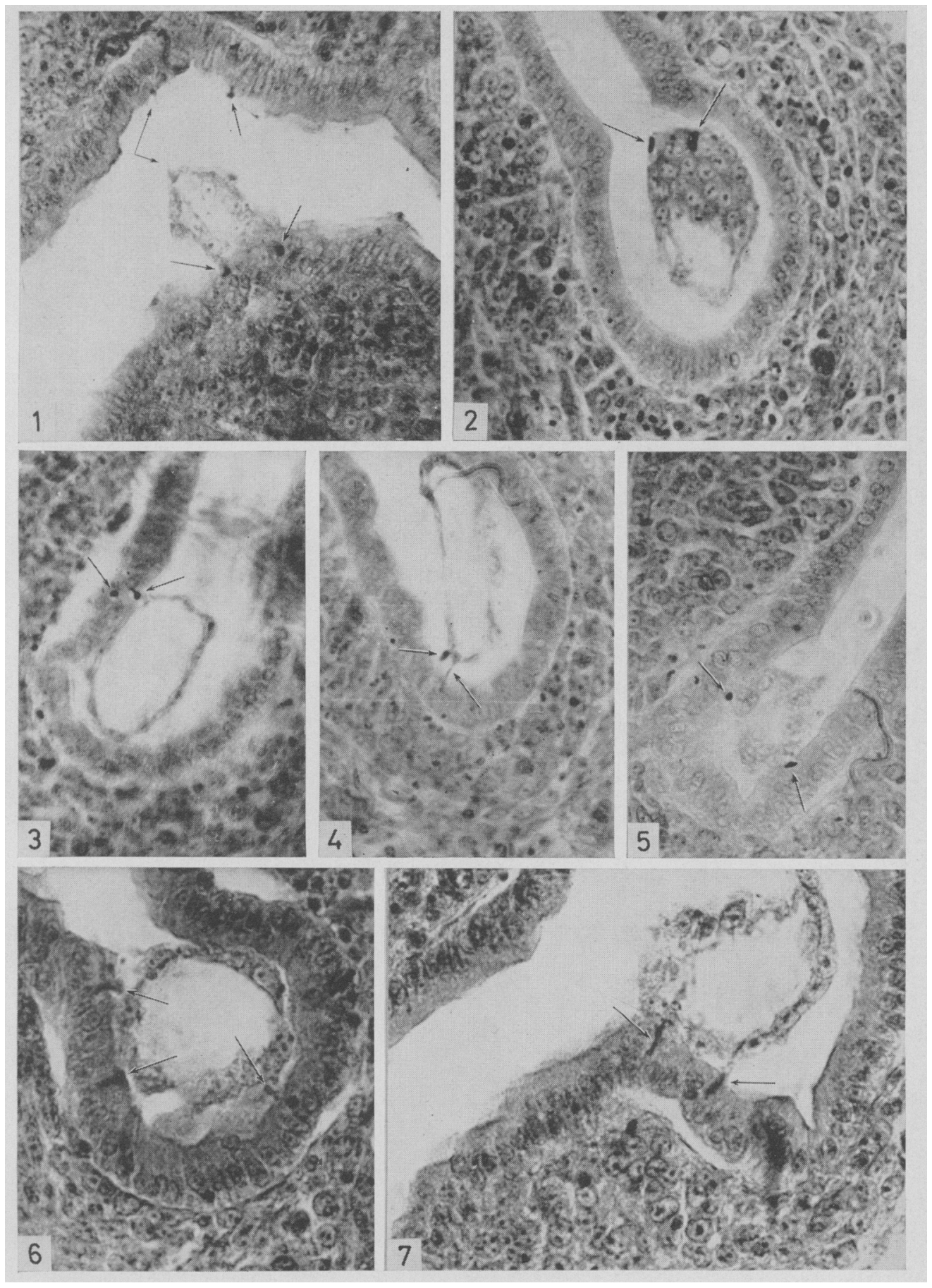




\section{Plate 3}

Frgs. 1 to 7. Transverse sections of blastocysts, showing W-bodies (indicated by arrows). Figs. 2 to 5 are of uteri stained with Methyl Green and Toluidine Blue, Figs. 1, 6 and 7 with iron haematoxylin. The focal plane has, in each case, been selected to show the W-bodies as clearly as possible, with the result that the rest of the section is often somewhat out of focus.

Fig. 1. A blastocyst from female 16, attached subterminally. One and perhaps two $W$-bodies are faintly seen in the uterine epithelium adjacent to the blastocyst; a further two are seen entering the uterine epithelium on the opposite side of the lumen, against which the blastocyst was pressed before fixation shrinkage took place. One of these was still attached to the blastocyst by a filament, which has broken; the broken ends of the filament can be seen protruding from the blastocyst and from the W-body. $\times 300$.

Fig. 2. The W-bodies in embryonic region of blastocyst. Female $5 . \times 300$.

Fig. 3. One $W$-body crossing from the blastocyst into the uterine epithelium, another possible $W$-body already in the epithelium. $\times 300$.

Fig. 4. Same blastocyst as in Fig. 2. Two W-bodies crossing from blastocyst into uterine epithelium, one of them stretched out to form a filament. $\times 300$.

Fig. 5. A different blastocyst, also from female 5. Two W-bodies entering the uterine epithelium. $\times 300$.

Fig. 6. Two W-bodies entering the uterine epithelium and a third about to enter. Female 22. $\times 400$.

Frg. 7. Two $\mathrm{W}$-bodies entering the uterine epithelium from a blastocyst at a subterminal attachment site. The antimesometrial end of the uterine lumen is at the bottom left-hand corner of the picture. Female 16. $\times 400$. 